\title{
El derecho ante el coronavirus covid-19: una visión a partir de la biojurídica*
}

\author{
The right before the coronavirus covid-19: a vision from the bio-legal
}

\author{
Sergio Trujillo Florián Ph.D** \\ Carlos Alfonso Laverde Rodríguez $* * *$ \\ IVÁN VARGAS-CHAVES $* * * *$
}

\begin{abstract}
* Artículo de reflexión producto del proyecto de investigación «Problemas biojurídicos del ejercicio de la prostitución en la jurisprudencia constitucional colombiana 2009-2018" del grupo de investigación "Derecho penal contemporáneo" de la Universidad La Gran Colombia y del Grupo de Investigación "Red de Estudios Sociojurídicos Comparados y Políticas Públicas -RESCYPP» de la Universidad Militar Nueva Granada.

** Abogado, especialista en Derecho Penal, Magister en Derecho Penal. Doctor en Bioética.Docente-investigador Grupo "Derecho Penal e implementación del Sistema Penal acusatorio". Facultad de Derecho, Universidad La Gran Colombia. Correo electrónico: edwin.trujillo@ugc.edu.co ORCID: 0000-0003-0772-0337

*** Sociólogo y Economista, especialista en historia del pensamiento económico con maestría en estudios políticos y sociales-UNAM, doctor en Ciencia social con especialidad en Sociología- Colmex. Correo electrónico: smials1@gmail.com. ORCID: 0000-0003-0772-0337

**** Doctor en Derecho. Profesor de la Universidad Militar Nueva Granada (Bogotá, Colombia). Contacto: ivargas@outlook.com; ORCID: 0000-0001-6597-2335
\end{abstract}

Fecha de recepción: agosto de 2020

Fecha de aprobación: diciembre de 2020

Para citar este artículo / To reference this article

Trujillo, s., Laverde, C.A., Vargas-Chávez, I. (2020) El derecho ante el coronavirus Covid 19: una visión a partír de la biojurídica Inciso, 22(2) ; 283-295

DOI: http://dx.doi.org/10.18634/incj.22v.2i.1089

\section{Resumen}

El presente artículo tiene como objetivo determinar la importancia de la biojurídica y la biopolítica para enfrentar una pandemia como el virus COVID - 19 . El virus ha hecho que esta época se torne difícil para todos los estratos sociales, su trascendencia es mundial, empero, sus consecuencias hacen que se visualice la pobreza y la inequidad. Los problemas evidenciados en salud pública, empleo informal y la distribución de los recursos en sectores privilegiados, hacen que el pánico se incremente y que las consecuencias sean nefastas para los más pobres 
de la sociedad. En situaciones como esta, la biojurídica, y el comunitarismo se presentan como medios morales disuasivos para la salvaguarda del otro por medio de decisiones que evitan la propagación del virus y sus consecuencias. Un hallazgo relevante es que el presente siglo ha permitido que una nueva ola de pensamiento social y económico tenga como punto de referencia la vida humana y no humana para la supervivencia del hombre frente a las nuevas tecnologías y las catástrofes venideras. La reflexión y el análisis de las unidades de observación se realizaron según la bioética, la biojurídica y la filosofía. El enfoque cualitativo permite describir y observar los fenómenos por medio de la hermenéutica para terminar con la respectiva inducción analítica. La conclusión principal es que la dignidad individual se ve confrontada con la dignidad colectiva y la superación de los problemas no tiene como fuente la ideología política.

Palabras clave: pandemia, Biojurídica, Biopolítica, paternalismo, comunitarismo.

\begin{abstract}
The purpose of this article is to present the current debate in the Colombian legal field, regarding the need or not, of the expertise in medical civil liability processes, through the analysis of the jurisprudence of the Sala de Casación Civil de la Corte Suprema de Justicia. Teaching, for this purpose, after a succinct context of the evidence on the matter, the description of the analyzed sentences, as well as the jurisprudential line that was elaborated, which reflects the treatment that this problem has historically received in one and another sense. Being transcendental, the recent discussion about whether "sound criticism", as the judge's evaluative criterion, must be integrated, in addition to common sense and the rules of experience, for a basic or advanced knowledge of the sciences. Being able to conclude that, according to the referred jurisprudential line, the first must operate, and based on this, the expertise, in such procedures, is generally established as a necessary requirement to manage the lawsuit and issue the ruling.
\end{abstract}

Keywords: pandemic, biolegal, biopolitics, paternalism, communitarianism.

\title{
Introducción
}

Este artículo se culminó el 30 de marzo de 2020, fecha en la que el mundo vive una etapa que está sacudiendo los paradigmas existentes en relación con el conocimiento de la bioética. Quienes consideran que la bioética no es más que un discurso ético para este siglo, deben sí o sí revaluar su teoría al enfrentar sus posturas ontológicas a la realidad de los problemas ambientales, económicos, sociales, y de salud como los que se están presentando (y los que se presentarán) con la pandemia COVID -19. Contrario a estas posturas, se considera que la bioética es una disciplina que se manifiesta en el saber científico, la práctica de la medicina clínica y en el caso que se estudia, el sistema jurídico y de poder por medio de las políticas públicas. 
En la pandemia COVID-19 las medidas que se han tomado para mitigar los efectos económicos y sus consecuencias en salud pública no han dependido de países a los que Colombia suele recurrir cuando necesita ayuda (Italia, España, Estados Unidos, Alemania, Brasil, entre otros, están en crisis). El Gobierno colombiano ha tenido que recurrir a su comunidad científica, al sector empresarial y a los asesores de todo tipo, como fuente en quienes están puestas las esperanzas para mitigar la pandemia.

La materialización de las medidas se da con la expedición de decretos presidenciales que permiten salvaguardar la vida de las personas y contener toda clase de problemas derivados de la pandemia. Por este motivo, en primer lugar, se describe el problema y la magnitud provocada por la llegada de la pandemia. Segundo, se hace necesario explicar cómo la bioética de la intervención (para ir más allá de la principialista) como fuente, hace que sus dogmas morales se manifiesten en el sistema jurídico, el resultado es la biojurídica.

De superar esta crisis, la reflexión se debe hacer a partir del aprendizaje y el crecimiento que tendrá la sociedad para solventar crisis venideras, porque, como se verá más adelante, este puede ser un ensayo para otras peores. Por este motivo, en el presente artículo se explica que una vez el aprendizaje se materialice, el Estado paternalista tendrá legitimidad al controlar la vida como política pública, sin entrar en arbitrariedades, dando paso a la biopolítica.

En tercer lugar, se explica el modelo comunitarista, que puede ser aplicado en la actualidad ante la emergencia que se vive, y es el más adecuado para poner en práctica la otredad como filosofía ética aplicable, como numeral de discusión en la presente reflexión. Por último, las reflexiones finales derivarán de lo descrito y analizado.

\section{Antecedentes}

Hasta finales del año 2019 y principios de 2020, el antropocentrismo ligado al neoliberalismo se presentó como una opción para enfrentar los "problemas" estructurales de producción de materias primas y explotación de recursos ecológicos que tenían apaciguada la economía mundial. Países como China, Estados Unidos, Brasil, entre otros, se encontraban en una carrera económica para determinar cuál sería la potencia al año 2030, hasta la llegada del COVID-19, el cual está afectando la salud pública y la economía mundial de forma catastrófica.

Según Pérez-Then (2020) los coronavirus humanos (HCoVs) se consideraron patógenos irrelevantes por mucho tiempo, por ejemplo, la gripe común, la cual puede afectar sin consecuencias mayores a toda la población. Dos HCoVs altamente patogénicos, el SARS-CoV y el MERS-CoV surgieron de reservorios animales con el fin de ocasionar epidemias con alta tasa de morbilidad y mortalidad en distintas partes del mundo. En diciembre de 2019 fue reconocido un nuevo coronavirus en Wuhan (China), en el cual se han reportado un número de casos crecientemente exponencial y ha hecho de las medidas de contención algo sin precedentes en la historia. 
El primer caso en Colombia se reportó el 06 de marzo de 2020 y hasta la fecha el Gobierno Nacional, departamentos y ciudades han decretado medidas con el fin de contener esta pandemia. Las disposiciones jurídicas han tenido poder declarativo, disuasivo, imperativo y prohibitivo. Por este motivo, surge la pregunta de qué tan importante es el bioderecho y la biopolítica para enfrentar una pandemia como el virus COVID - 19. Determinar su trascendencia hace que los modelos individualistas se vean coartados en beneficio del otro.

La importancia del bioderecho para contener el COVID-19 radica en la concientización de los seres humanos, porque cualquier acto del yo podría tener incidencia en el otro. Es decir, las consecuencias que se están evidenciando de esta pandemia hace que el otro tenga una relevancia que afecta al yo. El utilitarismo según John Stuart Mill (2005) realza la libertad y la autonomía del hombre sobre el presupuesto que él puede hacer todo aquello que no afecte a Ios demás. El utilitarismo expone que el Estado no puede obligar a una persona a realizar algo que le cause beneficio, ya que el ser es libre de hacer lo que le plazca, porque sus decisiones la afectan única y exclusivamente a ella, medidas propias de un Estado liberal.

Con la llegada del COVID-19, a diferencia del Estado liberal vuelve el Estado paternalista. Hasta la fecha han sido emitidos multiplicidad de decretos expedidos por el Gobierno Nacional, entre ellos, el Decreto 457 de 2020 que cita los términos de la sentencia T-483 de 1999 para justificar el aislamiento preventivo:

El derecho fundamental de circulación puede ser limitado, en virtud de la ley, pero sólo en la medida necesaria e indispensable en una sociedad democrática, con miras a prevenir la comisión de infracciones penales, proteger el interés público, la seguridad nacional, el orden público, la salud y la moral públicas, o los derechos y libertades de las demás personas, y en cuanto a la restricción sea igualmente compatible con el ejercicio de los demás derechos fundamentales reconocidos por la Constitución. Pero, como lo ha sostenido la Corte, toda restricción de dicho derecho debe estar acorde con los criterios de necesidad, racionalidad, proporcionalidad y finalidad; no son admisibles, por lo tanto, las limitaciones que imponga el legislador arbitrariamente, esto es, sin que tengan la debida justificación, a la luz de los principios, valores, derechos y deberes constitucionales (Corte Constitucional, 1999, p.35)

El objetivo de esta sentencia, la cual cita el decreto fue la salvaguarda de la libertad de locomoción en pro del orden público, lo cual ha servido de base para justificar un decreto que a todas luces evidencia el resurgimiento del paternalismo en momentos de crisis. El análisis que se debe hacer radica en la importancia del contenido axiológico de toda clase de normatividad, lo cual se efectuará a partir de las siguientes variables.

\section{Bioética, bioderecho y biopolítica - punto de encuentro}

Casado (2011) considera que la bioética es una rama de la ética que se dedica a profundizar acerca de los principios que deben tenerse en cuenta para la adecuación del comportamiento del ser humano y su relación con la vida humana y no humana. Es la ética del siglo XXI, porque regula aquellos códigos morales de conducta que permiten la humanización del hombre en su relación con las especies. La bioética inicialmente estaba dirigida a la salvaguarda de los cuatro 
principios que regulan la actividad clínica, sin embrago, este modelo principialista se ha ido extendiendo con los años y conforme a los avances sociales y tecnológicos.

Torres, Tirado y Trujillo (2018) han resaltado la importancia de tomar la bioética como punto de partida para la toma de decisiones en el marco del derecho en general con el fin de garantizar el principio de Dignidad Humana, no solo en su individualidad, sino en su relación con la sociedad. Son numerosos los autores que proponen que el sistema normativo jurídico debe contener los valores expuestos por la bioética, porque esta disciplina otorga estándares de protección para la Dignidad Humana y la colectiva. En este sentido, Miralles (2007) considera que la bioética es una disciplina ética.

El contexto tradicional del Derecho hace que este administre la naturaleza y su regulación, sin embargo, los dilemas de la bioética nacen cuando se imponen las diversas percepciones sociales que hacen que lo natural se convierta en difuso y traspasan los límites de lo artificial de la vida. Es decir, el derecho tradicional es capaz de adaptarse a cualquier circunstancia que demanda la vida, sin importar el análisis moral del asunto, mientras que la bioética trata de conducir el actuar en los mínimos de moralidad para lograr humanizar la conducta del ser. El Derecho debe ir más allá de regular contratos.

D’Agostino (2002) señala que a pesar que se ve lejana la posibilidad de tener un código bioético, se tienen los instrumentos internacionales como la Declaración Universal sobre Bioética y Derechos Humanos (DUBDH) de 2005, expedida por la UNESCO, los cuales proporcionan criterios de racionalidad y racionalización para que los juristas reflexionen sobre el estado real de las cosas antes de tomar decisiones, esto implica la renuncia de dogmas que no le permiten al Derecho ver más allá.

La DUBDH significó un rompimiento entre la bioética clínica clásica de principios, la cual no contenía una visión social y política. Por lo tanto, frente a los que consideran que la bioética es un simple discurso que no puede ser denominado disciplina, es necesario afirmar que la bioética se materializa por medio de los instrumentos jurídicos que permiten la convivencialidad y la relación entre los hombres para sobrevivir un poco de tiempo más. Sin embargo, hay que aclarar que el Derecho sirve como instrumento de justificación de conductas que podrían socavar la dignidad del hombre y la sociedad, a esto se le denomina bioética complaciente, término acuñado por Serrano-Ruíz-Calderón (2013).

Una alternativa para evitar que el Derecho se torne como un factor justificador de conductas amorales es supeditándolo a la bioética, por lo tanto, se da el nacimiento de la biojurídica. Miralles (2007) afirma que el término "biojurídica" tiene relación con la filosofía del Derecho, no con diseños positivos estructurales de normas civiles, penales. Por lo tanto, Trujillo (2019) considera que la biojurídica se presenta en toda clase de normas expedidas sea por el Gobierno o ejecutivo (decretos, resoluciones, acuerdos), el legislativo (leyes) o la rama judicial (jurisprudencia, autos) que buscan regular las relaciones entre los seres humanos y con la vida, por tanto, en este sentido se analiza su contenido moral y de principios. 
La biojurídica denominada como el Derecho con principios bioéticos, debe propender por la legislación de todo tipo que elimine la pobreza extrema, el acceso al agua potable, un medio ambiente sin contaminación, la garantía de la alimentación, desarrollo sostenible, acceso a los servicios públicos, entre otros. Además de todos estos problemas, la biojurídica tiene también la función de analizar los problemas vinculados con salud pública y la medicina social. En el caso del COVID-19 las normas diseñadas por los gobernantes territoriales deben contener principios que busquen garantizar el mínimo vital en épocas de crisis.

En este sentido Bergel (2015) resaltó los esfuerzos de la bioética para convertirse en un movimiento social y cultural en pro de la vida y la salud, además, consideró que ya están dadas las condiciones para la suscripción de un instrumento jurídico que lleve a un tratado internacional sobre bioética, ya que los principios de la DUBDH ya han sido discutidos ampliamente en todo el mundo. Una sugerencia es que una vez superada la crisis del COVID-19 los países deben suscribir un tratado internacional de bioética. En este sentido Bergel afirma:

Los movimientos sociales han demostrado su efectividad más allá de la existencia o inexistencia de las normas legales. Un ejemplo incuestionable fue la reacción social, no solo interna sino también extendida en el plano internacional en el caso de los medicamentos para combatir el SIDA, lo que llevó al gobierno sudafricano a ignorar los tratados destinados a permitir que sus habitantes tengan acceso a medicamentos esenciales; un ejemplo más adelante fue el de Brasil que bajo la administración de Lula da Silva, finalmente condujo a moderar el Acuerdo de Doha respecto a la propiedad industrial. (Bergel, 2015,p.453) [Traducción propia].

Por esta razón, es pertinente que una vez superada la crisis mundial, los países unan sus esfuerzos para crear un estatuto con fuerza de tratado internacional que pueda establecer un enfoque biocentrista y que obligue a los Estados a adoptar el sistema jurídico a la bioética, con lo cual se podría obtener una verdadera biojurídica. En el contexto colombiano, se observa la expedición de decretos en los que se manifiestan principios que propenden por garantizar el buen servicio de salud y que este no colapse.

Las medidas adoptadas en Colombia corresponden a una emergencia mundial y no al factor preventivo. Una vez la bioética haya permeado el sistema jurídico, las consecuencias se deben evidenciar por la capacidad que tienen los Estados de hacer realidad todas las medidas adoptadas, la biopolítica es la respuesta. Trujillo (2019) propone que la biopolítica se entienda como aquel ejercicio del poder con enfoque bioético.

Es decir, la biopolítica necesariamente significa el ejercicio del poder por medio de políticas públicas que hacen que el Estado vigile, modifique y la actividad de la sociedad con el fin de fortalecer el bios para que pueda reaccionar frente a las problemáticas. El concepto de biopolítica que se conoce en la actualidad fue desarrollado por Foucault (1990), quien proporcionó los postulados para conectar el bios y el zoe para afirmar que el Estado ejerce un biopoder como estilo de gobierno que genera impacto en las vidas de las personas. El concepto biopolítico actual radica en que la vida y la política deben ir juntas como medios de poder y autovigilancia. Sin embargo, posiciones críticas del biopoder han sido reseñadas ante la crisis del COVID-19, 
Latour (2020) afirma que a pesar de que esta es una buena oportunidad para reflexionar sobre lo importante e irrisorio, se ha retrocedido al Estado del siglo XIX por el excesivo control hacia las personas para que queden atrapados en sus casas y la destrucción de los trabajadores ocultos para que muchos puedan seguir encerrados.

\section{Comunitarismo como filosofía en época de crisis}

El comunitarismo es visto como una filosofía política que busca enfocarse en lo moral y axiológico y las instituciones básicas que unen la sociedad. En este contexto, Andrade (2008) considera que la solidaridad debe estar por encima de lo presupuestado en un contrato social para no rechazar al pobre. Por lo tanto, volver a un Estado paternalista no solamente implica una entrega de los derechos para que las instituciones los salvaguarden, sino también la solidaridad de los coasociados.

En un sentido aristotélico, lo social crece cuando los valores morales como la solidaridad en épocas de crisis justifican las actuaciones del Estado, el cual debe propender no solamente por los derechos individuales, sino los colectivos. La sociedad eminentemente neoliberal oculta el enfrentamiento entre el capitalismo y la democracia, el resultado de esta disputa es el rechazo a todo aquello que no produzca ni genere capital. El neoliberalismo hace que la pobreza se haga más evidente por la inequidad de la distribución de los recursos, esto, combinado a que en una sociedad de consumo los derechos individuales emergen por encima de los sociales.

El comunitarismo ético permite comprender que aunque cada miembro es único, le debe rendir cuentas en conducta moral, justa no solo en relación consigo mismo, sino hacia el otro. Latour (2020) considera que la crisis que se está viviendo es un ensayo frente a peores problemas venideros, porque problemas de salud pública no son novedosos en la historia de la humanidad. Por lo tanto, el comunitarismo se presenta como la opción de parcialización de los derechos y las obligaciones de los habitantes frente a los demás y lo que está viviendo la sociedad colombiana a marzo de 2020 puede convertirse en una oportunidad de crecimiento moral social y para que el Gobierno nacional implemente una verdadera biopolítica.

Los comunitaristas critican al liberalismo, sin embargo, el propósito de esta variable no es realizar una comparación. El real objetivo es establecer los presupuestos que permiten reflexionar sobre qué modelo político y filosófico es el más adecuado para enfrentar una crisis. Los debates entre los postulados de Keynes, Hayek, Friedman, o Rothbard vienen a solucionar problemas que se presentan de acuerdo con cada contexto, luego, cada teoría ha resultado exitosa en un contexto histórico, como también han tenido su desuso. Por ejemplo, una vez culminada la Segunda Guerra Mundial, las teorías de intervención estatal fueron efectivas para corregir los desequilibrios del mercado y hacer de naciones como los Estados Unidos potencias, pero una vez agotado el modelo keynesiano de impulso a la demanda agregada mediante la participación activa del gasto público, la apuesta de renovación del liberalismo, que hacía carrera desde la década de los treinta, tomó fuerza y se impuso, desde finales de la década de los setenta, de la mano de las teorías de la escuela austriaca y de Chicago. 
El siglo XXI ha permitido que una nueva ola de pensamiento social y económico tenga como punto de referencia la vida humana y no humana, con el fin de buscar la supervivencia del hombre frente a las nuevas tecnologías y las catástrofes venideras, a lo que hemos denominado enfoque biocentrista. Aquel que hace que la bioética global sirva de puente entre la ciencia y lo humano. Judt (2010) en una crítica acérrima hacia las políticas neoliberales considera que el estilo egoísta de lo contemporáneo resulta natural. Durante años la sociedad ha buscado el beneficio material, y eso es lo único colectivo que los identifica: "Sabemos qué cuestan las cosas, pero no tenemos idea de lo que valen" (p.17). En este sentido, el discurso liberal ha hecho que el estilo materialista y egoísta de la vida contemporánea haga parte de la condición humana y la crisis del COVID -19 y las que quizá vendrán van replantear esta disertación.

El manejo de la crisis por parte de algunos países dependen de sus políticas económicas y estas van a primar sobre la vida humana, a fecha del 27 de marzo de 2020 se evidencia el tono discursivo de los gobiernos de Estados Unidos, Brasil e Inglaterra, para quienes prima la economía sobre la salud pública ${ }^{1}$ a pesar de que el virus crezca exponencialmente. Esto ya se había advertido:

Las instituciones de la república han sido degradadas, sobre todo por el dinero. Peor todavía, el lenguaje de la propia política se ha vaciado de sustancia y significado. Una mayoría de estadounidenses adultos no está satisfecha con la forma en que se gobierna, en que se toman las decisiones y con la influencia desmedida de los intereses especiales. En el Reino Unido los sondeos de opinión indican que la desilusión, los aparatos de los partidos y sus políticas no ha sido mayor. No deberíamos ignorar estos sentimientos. El fracaso democrático trasciende las fronteras nacionales. El vergonzoso fiasco de la Cumbre del Clima de Copenhague en diciembre de 2009 ya se está traduciendo en cinismo y desesperanza entre los jóvenes: ¿Qué va a ser de ellos si no nos tomamos en serio las implicaciones de un calentamiento global? El desastre sanitario en Estados Unidos y la crisis financiera han acentuado la sensación de impotencia incluso entre los votantes con mejor voluntad. Hemos de actuar por nuestra intuición de una catástrofe inminente (Judt, T. 2010,p.160)

Es necesario afirmar que el virus COVID-19 afecta en su mayoría a las personas adultas mayores, el resultado de las medidas adoptadas por los países que han minimizado el virus para enfocarse en la producción se verán a finales de 2020, de seguro la disconformidad seguirá en la población mayor adulta sobreviviente, a este fenómeno Arribas, Cattaneo \& Ayerdi (2004) lo denominó "canibalismo social" descrito como aquel que nace cuando una sociedad sacrifica personas para el crecimiento y el desarrollo de otros. Esto, sin contar el impacto que generará en la conciencia de la juventud las medidas tomadas. En este sentido la bioética norteamericana tendrá que enfrentarse al dilema salud o economía, así como los médicos en Italia deben escoger entre varios pacientes a cuál salvarle la vida.

La vuelta al comunitarismo es una apuesta que seguramente tomará un particular realce ante una crisis del modelo, no solo económico, sino del supuesto epistemológico del individualismo metodológico que le subyace. Siguiendo el argumento que expone Samir Amin (1989) si el

1. Para Donal Trump, presidente de los Estados Unidos, su país no está diseñado para cerrar o confinarse, la economía no debe sacrificarse por una enfermedad que considera insignificante, noticia consultada el 28 de marzo de 2020. ver en https://www.semana.com/mundo/articulo/coronavirus-donald-trump-se-niega-a-decretar-la-cuarentena-en-estados-unidos/658904 
sistema capitalista ha logrado imponer un discurso unificado de democracia y mercado, la actual crisis del mercado y de respuesta del Estado ante la pandemia, en el mejor de los casos, sacudirá sus supuestos herederos de la era republicana del siglo XIX.

Como lo ha venido planteando Bruno Latour (2005) desde los años ochenta con el desarrollo de la teoría del actor-red, la actual situación de la sociedad depende no exclusivamente de un Estado vigilante que planea y dirige demográficamente desde arriba a través de estadísticas, sino desde la comprensión de la asociación entre muchos actores o como lo denominará en su teoría seres actantes de los cuales algunos no tienen formas humanas. En este sentido el Estado moderno debe dar un paso de su posición del padre que enseña a sus ciudadanos al Estado que aprende y mantiene las condiciones de habitabilidad de los actantes, no únicamente humanos, porque como lo menciona el mismo autor con precisión: "El patógeno cuya terrible virulencia ha cambiado las condiciones de vida de los habitantes del planeta no es el virus en sí mismo, jes la humanidad" (Latour, 2020) [Traducción propia].El reto del Estado no depende únicamente de actuar con rapidez con fórmulas conocidas. El giro del Estado radica en la comprensión de que los ciudadanos no responden y actúan de una manera individualizada y bajo los principios del homo economicus. Actuamos como una compleja red que excede los principios jerárquicos clásicos de la sociedad occidental. La comunidad ha tomado realce en una crisis en la que el problema de salud, aunque con deficiencias es atendido, mientras gran parte de la población busca formas de sobrevivencia que permitan permanecer en nuestras casas a quienes tenemos el privilegio de hacerlo.

Las nuevas lógicas que deben emerger de un Estado renovado que son aquellas que impidan el lapidario futuro cercano que anuncia Butler (2020), al afirmar que seremos testigos de un escenario en el que algunos afirmarán su derecho a vivir a expensas de otros.

\section{Discusión: La otredad y las consecuencias inevitables}

"Tanto una forma de representación de la amenaza como la otra, comparten la peligrosidad de sus efectos disgregantes sobre un orden social y la remisión a la imagen de sujetos que reclaman desde el límite de su necesidad, aquello que les ha sido privado y a lo cual tienen derecho, un derecho natural: la subsistencia"

Victoria Arribas et al

El pensamiento del yo hacia el otro como aquel que excede todo derecho individual, no solo debe estar ligado hacia la evitabilidad del contagio, sino de las consecuencias económicas que surgirán por la llegada de la pandemia. El dilema que nace en la crisis producida por la pandemia hacia el otro es piedad o miedo. El problema es manifestar la piedad hacia el otro sin acercarse, además, el miedo a ser contagiado es otro factor que aleja.

La filosofía tradicional occidental siempre ha estado preocupada por el estudio del yo, Kaminsky (2014) afirmó que en la dinámica de la otredad se traza la idea del semejante: "Otro al que le puedo dar cabida en el mundo de la mismidad, el prójimo" (p.31), el caso estudiado, la crisis por 
la pandemia COVID-19 pone en evidencia esa mismidad de la que habla el autor, es decir, pone en un plano de igualdad a toda la sociedad en su humanidad. El inconveniente que surge es que unos pueden protegerse mejor que otros. Las consecuencias socioeconómicas no son iguales para la clase alta que para los pobres. Lévinas (1996) considera que el otro es todo lo que excede al yo, todo aquello que es diferente, el otro desborda al yo porque es infinito, lo excede, lo saca de sí, incomoda porque es quien necesita entrar. Por lo tanto, no es un encuentro de dos, tres o más, sino entre.

La importancia de la enseñanza de la otredad por medio de la biojurídica permite que las personas obren de acuerdo con sus capacidades en hospitalidad para con el excluido, el marginado, el pobre, porque la ética social accede comprender que la mismidad no es el camino para que la sociedad pueda crecer en valores. La sociedad se debe a los menos favorecidos, el acercamiento hospitalario es esencial para que los desposeídos puedan recibir lo que se les ha quitado por una desacertada distribución de los recursos.

Surge la imperiosa necesidad de reflexionar acerca de las distancias sociales para crear un lazo de conexión con aquellos que necesitan de un acercamiento más efectivo. Conforme a las anteriores explicaciones, el propósito de la biojurídica es que las resoluciones y los decretos expedidos por el Gobierno Nacional y distrital tengan un efecto en la conciencia de cada persona. Quien se resguarda no debe pensar en las multas como factor disuasivo, sino en el daño que se puede hacer a sí mismo y al otro bajo el principio de una comunidad, aunque no vinculada por los lazos del parentesco o el conocimiento mutuo, aquello que denominó Anderson (1993) como comunidades imaginadas.

Las medidas adoptadas deben sintetizar el biopoder como medio de control social para la salvaguarda de la población en general, sin tener que sacrificar a los más pobres. En esta crisis, la construcción de un espacio invisible que permita a los benefactores no excluir a los que reciben. Todos tienen algo que dar bajo el lema popular: "Siempre habrá alguien peor", por lo tanto, hay personas de los estratos 3 y 4 que no tienen poder económico para dar frente al desposeído, deben por lo menos limitar sus derechos de libre circulación para evitar la propagación de la pandemia, máxime cuando va a llegar a los que no tienen acceso a la salud.

El COVID-19 ha hecho que el Gobierno Nacional y la administración distrital dejen de lado los intereses ideológicos partidistas y se estén preparando para el inminente infortunio económico que se sentirá por las medidas de aislamiento y cuarentena obligatoria para contener la propagación del virus. Más que grupos de expertos para analizar los efectos que dejará en la ciudad de Bogotá en contexto con el PIB, el empleo, la salud, se necesita la comprensión de la necesidad de las reservas económicas estatales a futuro.

Sectores como el turismo, hoteles, restaurantes, comercio, transporte, aviación, servicios de autopartes, sector de la construcción, conciertos, espectáculos, atracciones, flores, bares, discotecas son los sectores afectados con esta pandemia. Sin embargo, los vendedores informales (Ilamados ambulantes), que según los datos del Instituto para la Economía Social (IPES) rondan por las 85.000 personas, vienen a ser los más afectados porque trabajan en la informalidad con bajos ingresos y personas que dependen de ellos. Al terminar la contingencia 
sus niveles de pobreza aumentarán y disminuirán las posibilidades de acceder a una canasta familiar básica. Las medidas que se tomen incluirán el compromiso de todos.

En principio se busca evitar el contagio, sin embargo, como se advirtió en numerales anteriores, es un virus que afecta principalmente a la población mayor de 65 años, las medidas de aislamiento preventivo deben preocupar al Gobierno para implementar acciones dirigidas a la población más pobre para que no pase hambre y tengo lo mínimo para vivir. Se piensa en un sistema unificado de transferencias: monetaria, de bonos por bienes y servicios para canjear. Además, acceso a congelamiento de deudas y servicios públicos. La ciudad debe buscar una herramienta jurídica que le permita utilizar aproximadamente 9 billones de pesos que se han ahorrado en presupuestos anteriores sin ejecutar.

La educación es otro punto de dificultad, la directriz por parte del Ministerio de Educación es no dejar de prestar el servicio hacia la población estudiantil de todos los niveles y virtualizar para que desde sus casas los estudiantes puedan acceder a las clases y al material didáctico. Para solventar esta necesidad se ha tenido que recurrir a la virtualización como herramienta. En los estratos altos no hay dificultad para que tanto docentes como estudiantes naveguen en la red y equipos para el acceso a las TIC. El problema surge para los estratos bajos, donde no se tiene un computador, ni mucho menos internet, o existe un computador para familias numerosas, en los que solo hay un equipo que se utiliza para teletrabajo, educación de varios de sus integrantes. Esto no solo pasa con estudiantes, sino también con profesores. El COVID -19 ha evidenciado este inconveniente.

El pensar en el otro es un reto que se plantea desde todos los niveles, pensar en la necesidad de un rico no representa un verdadero desafío, medidas asumidas por establecimientos educativos universitarios Ilamados de élite no tienen estos problemas. Mientras que en el sector emergente se hace manifiesto que los pobres y sus hijos que permanecen en el colegio tendrán menos posibilidades de rendimiento eficiente en su aprendizaje, en su nutrición y en el futuro su empleo será menos gratificante y peor pagado.

En época de crisis, como la actual el otro es el pobre, el desamparado, el que no tiene los medios para solventar sus necesidades porque vive del día a día, el habitante de la calle, el extranjero, la madre soltera, en fin, las medidas biojurídicas adoptadas por el Gobierno deben tener un contenido filosófico más que paternalista, el comunitarismo puede inmiscuirse, para que las motivaciones puedan concientizar a la ciudadanía y poder ayudar a mitigar la contingencia en lo posible para la construcción de una biopolítica futura y eficiente.

\section{Conclusiones}

La dificultad de reflexionar acerca de un evento que se está presentando, deriva del cuidado de los datos suministrados en el documento. Lo único que se puede afirmar con certeza es que superada la crisis, el aprendizaje como sociedad será amplio. De los gobiernos depende que las crisis venideras puedan solventarse mejor y que la afectación hacia los más pobres no se manifieste. Esta es la materialización de la bioética, pues la misma permite ser un puente entre la ciencia y lo humano, entre la crisis y la solución humana. 
La biojurídica permite humanizar los actos administrativos en pro de los derechos individuales que pueden afectar a la persona y a los demás. Más allá de pensar en un Estado paternalista y de hacer una crítica al liberalismo en épocas de crisis, los fundamentos filosóficos de las acciones legislativas deben tener inmersas filosofías como el comunitarismo y el cuidado por el otro. La biopolítica como ejercicio del poder con tendencia bioética se manifestará si el Gobierno Nacional permite que exista mejor inversión en ciencia y salud pública.

Se concluye que en medio de esta crisis, la dignidad individual se ve confrontada con la dignidad colectiva, cabe destacar las acciones de empresarios que han garantizado los empleos y las acciones de líderes políticos que han unido sus esfuerzos en pro de superar la contingencia. La superación de los problemas no tiene como fuente la ideología política.

\section{Referencias}

Amin, S. (1989). El eurocentrismo. Crítica de una ideología. Madrid: Siglo Veintiuno Editores.

Anderson, B. (1993). Comunidades imaginadas: reflexiones sobre el origen y la difusión del nacionalismo. México: Fondo de Cultura Económica.

Andrade, M. (2008). ¿Qué es la "aporofobia”? Un análisis conceptual sobre prejuicios, estereotipos y discriminación hacia los pobres. Agenda Social, 2(3), 117-139.

Arribas, V. Cattaneo, A. \& Ayerdi, C. (2004). Canibalismo y pobreza. Constructores de la otredad. Buenos Aires: Antropofagia.

Bergel, S. D. (2015). Ten years of the Universal Declaration on Bioethics and Human Rights. Revista Bioética, 23(3).

Butler, J. (2020). "El capitalismo tiene sus límites". En Sopa de Wuhan. Pensamiento contemporáneo en tiempos de crisis.

Casado, M. (2011). "Sobre las relaciones entre la bioética y el derecho", Revista Bioética (Conselho Federal de Medicina CFM, Brasil), Vol.19 Nº1, pp. 15 - 28.

Colombia. Presidencia de la República - Ministerio del Interior. Decreto 457. (22 de marzo del 2020). Por el cual imparten instrucciones en virtud de la emergencia sanitaria generada por la pandemia del Coronavirus COVID-19 y el mantenimiento del orden público. Bogotá, D. C., 2020.

Colombia. Corte Constitucional Sala Plena. (8 de julio de 1999) Sentencia T-483. M.P. Antonio Barrera Carbonell. Disponible en http://www.corteconstitucional.gov.co/ relatoria/1999/t-483-01.htm

D’Agostino, F. (2002). Bioética y derecho. Acta bioethica, 8(2), 177-182.

Foucault, M. (1990). Vigilar y castigar: nacimiento de la prisión. Madrid: Siglo XXI.

Judt, T. (2010). Algo va mal. Traducción de Belén Urrutia. Bogotá: Prisa ediciones. 
Kaminsky, G. (2014). "Entre la mismidad y la otredad". Publicación de Ciencias Sociales que lleva adelante la Carrera de Trabajo Social de la Facultad de Ciencias Sociales de la Universidad de Buenos Aires, con el objetivo de generar un espacio de debate y difusión de conocimiento social., 31.

Latour, B. (2020). Is This a Dress Rehearsal?. In the moment en: https://critinq.wordpress. com/2020/03/26/is-this-a-dress-rehearsal/

Latour, B. (2005). Reassembling the Social An Introduction to Actor-Network- Theory. New York: Oxford University Press.

Lévinas, E. (1996). Entre nosotros. Madrid: Pre-textos.

Miralles, A. A. (2007). Bioética, bioderecho y biojurídica (Reflexiones desde la filosofía del derecho). Anuario de filosofía del derecho, (24), 63-84.

Mill, J. S. (2005). Sobre la libertad. Madrid: Eda.

Pérez-Then, E. (2020). Nuevo coronavirus 2019-ncov: impacto en salud global. Ciencia y Salud, 4(1), 5-9.

Serrano-Ruiz-Calderón, J. M. (2013). "Sobre la injusticia de la eutanasia. El uso de la compasión como máscara moral. Referencia a nuevos documentos bioéticos europeos». Persona y Bioética, 17(2).

Torres Vásquez, H., Tirado Acero, M., \& Trujillo Florián, S. (2018). El funcionalismo radical penal a partir de la bioética. Revista republicana, (25), 179-198.

Trujillo, S.F. (2019). La dignidad y la Justicia para el drogodependiente habitante de la calle. problemas jurídicos de la legalización. (Tesis doctoral).Recuperado de https://repository. unimilitar.edu.co/bitstream/handle/10654/32686/TrujilloFlori\%C3\%A1nEdwinSecergio2019.pdf?sequence=2 